\title{
Rotary-Vane Attenuator With an Optical Readout
}

\author{
W. E. Little*, W. Larson*, and B. J. Kinder* \\ Institute for Basic Standards, National Bureau of Standards, Boulder, Colorado 80302
}

(May 13, 1970)

\begin{abstract}
A precision $\mathrm{x}$-band rotary-vane attenuator has been developed that follows its theoretical cosine squared law of attenuation to within $0.002 \mathrm{~dB}$ to a value of $20 \mathrm{~dB}$. The best available attenuation measurement techniques verify this relationship to within the accuracy of the measurements. From 20 to $50 \mathrm{~dB}$, the deviation from the theoretical value slowly increases and is frequency dependent. At present, three attenuators of this type have been constructed by NBS. Two of these attenuators have excellent attenuation versus frequency characteristics in the 20 to $50 \mathrm{~dB}$ range $(0.08 \mathrm{~dB}$ deviation at $50 \mathrm{~dB})$ while the third has a marked degree of frequency sensitivity $(0.21 \mathrm{~dB}$ at $50 \mathrm{~dB})$.
\end{abstract}

Key words: Attenuator; microwave; precision; rotary vane.

\section{Introduction}

The principle of the rotary-vane attenuator $[1,2]^{1}$ has been known for a number of years, and relatively good attenuators have been commercially available for some time. A considerable amount of analysis $[3,4,5,6,7]$ of this type of commercially available attenuator has been made, and some work has been directed toward the development of more precise attenuators [8,9]. Most of the major problems have been identified and analyzed.

The steps taken in the work described in this paper were to eliminate or reduce the major limiting errors. The results achieved using this approach were very gratifying. The evaluation of the three constructed attenuators has shown that the property of attenuation difference up to 20 $\mathrm{dB}$ is improved an order of magnitude over that reported previously. However, two of the attenuators retain their excellence above $20 \mathrm{~dB}$, while the third shows some frequency dependence at higher values of attenuation. A description of the attenuators and the results of the measurement on two of them by the $\mathrm{i}-\mathrm{f}$ substitution [10], $\mathrm{d}-\mathrm{c}$ substitution [12], and modulated subcarrier [13] techniques of attenuation measurement are given.

The "true" rotary vane value is estimated by averaging the results from the three measurement techniques. Measurement results from the third attenuator by the subcarrier technique are also given.

\section{Theory}

As is well known, the ideal behavior of the rotary-vane attenuator is given by

\footnotetext{
* National Bureau of Standards, Electromagnetics Division, Boulder, Colo. 80302 1 Figures in brackets indicate the literature references at the end of this paper.
}

$$
\frac{E_{\text {in }}}{E_{\text {out }}}=\frac{1}{\cos ^{2} \gamma}
$$

where $E_{\text {in }}$ indicates the strength of the input wave and $E_{\text {out }}$ is the strength of the output wave.

In decibels, this is

$$
A=-40 \log _{10}(\cos \gamma) .
$$

Thus, ideally, the output wave is a simple function of the angle of rotation of the center section of the attenuator.

There are many problems encountered in the actual construction of this type attenuator which has many sources of error. The errors fall roughly into five categories: (1) read-out resolution and resettability; (2) basic mechanical precision such as vane alinement, rotating section eccentricity, resolution of vane angle setting, etc.; (3) external leakage, primarily from the rotating joints; (4) internal leakage (lack of absorption of the parallel component); and (5) internal reflections. Mariner [8] gives adequate analysis of categories 2, 4, and 5. James [9] also considers these errors as well as category 1 for the particular type tape readout which he was using. Larson [7] further considers the vane alinement error. The errors caused by category 3 have not been considered and in fact have not been readily observable in the attenuators that have been tested to date, primarily because there was not sufficient resolution to see the results of the leakage or the problem was not identified. In the development of the attenuators described here, this problem was identified and had to be corrected for before substantial improvement could be accomplished. 


\section{Description of the Attenuator}

\subsection{Readout}

One of the major limitations of the design of this type of attenuator has been the technique used to determine the actual vane angle setting. In the commercial lowresolution (and some recent high-resolution) instruments, the technique is to simply use a gear reduction system with all the associated mechanical problems. These errors have been analyzed by Larson $[4,6]$ and it is quite conclusive that the technique rapidly becomes the limiting factor in the design of an ultra-precision attenuator. James [9] used a tape-dial indicator arrangement but, again, it is not suitable for ultra-precision attenuators. (See fig. 1.)

To achieve the desired accuracy, the readout has to be a direct-reading device attached directly to the rotating cylinder. Fortunately, there are commercially available engraved glass scales with an optical readout that have the desired accuracy and resolution. Figure 2 shows a sketch of one of the scales mounted on the cylinder of the attenuator's rotating center section. The scale has an absolute accuracy of $\pm l^{\prime \prime}$ of arc and a resolution of the same amount; hence, the total uncertainty is $\pm 2^{\prime \prime}$ of arc. Figure 3 shows the attenuation deviation in $\mathrm{dB}$ from nominal for the variation of $\pm 2^{\prime \prime}$ of arc versus attenuator dial

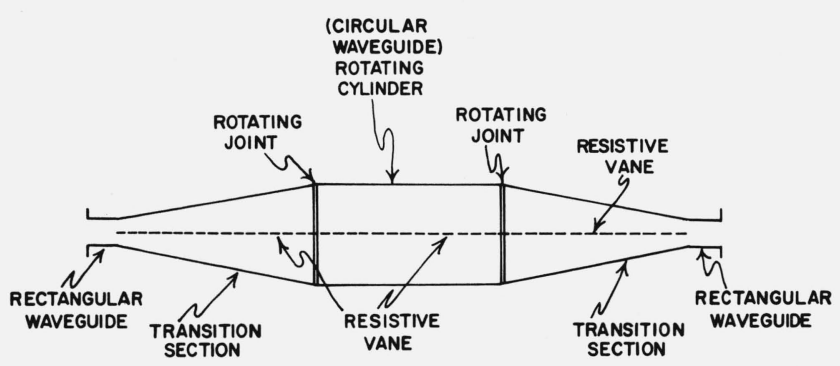

FIGURE 1. Basic components of rotary-vane attenuator.

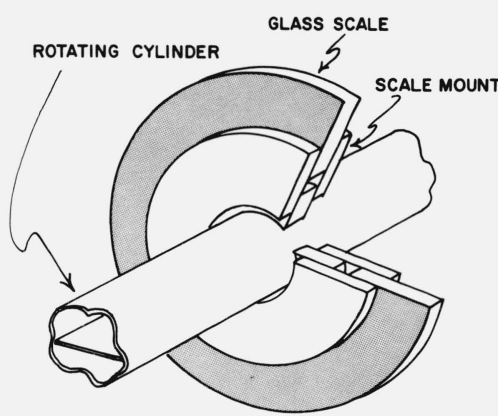

FigURE 2. Engraved glass scale mounted on rotating cylinder.

setting in decibels. If this were the only source of uncertainty, the values of the uncertainty in attenuation would be about $\pm 0.00025 \mathrm{~dB}$ and $0.003 \mathrm{~dB}$ at the dial setting of 10 and $50 \mathrm{~dB}$ respectively.

A sketch of the dual microscope readout is illustrated in figure 4 . Note the two viewing apertures are located 180 degrees apart in order to reduce the eccentricity error.

\subsection{Mechanical Precision}

The final quality of the attenuator, even with the engraved scales, is primarily a function of the precision and accuracy with which it is assembled. Larson [7] shows that the vane alinement is quite critical and a relatively small misalinement can cause a considerable error. Further, in order to utilize effectively the $\pm 1^{\prime \prime}$ of arc resolution of the engraved scale, rotational precision is a must.

The required precision was obtained by carefully machining and strengthening the attenuator housing as shown in figure 5 . In some of the later testing of attenuator No. 1, it was observed that even with the improved housing there was a nonrepeatability of setting of approximately $10 \mu \mathrm{B}$. The cause of this problem was found

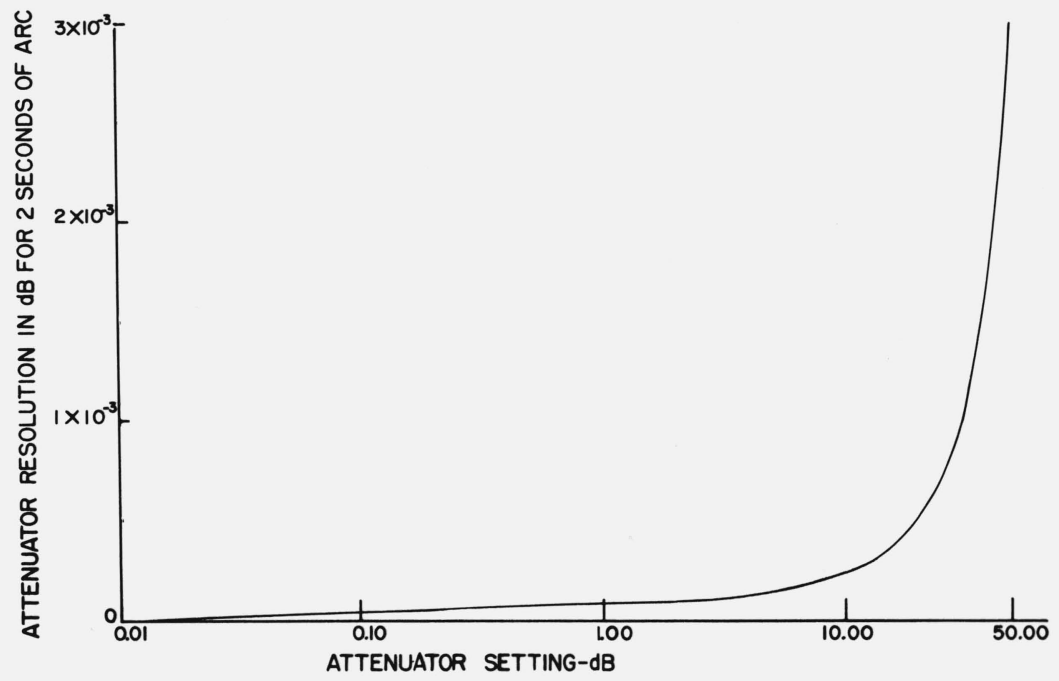

FigUre 3. Attenuator resolution. 


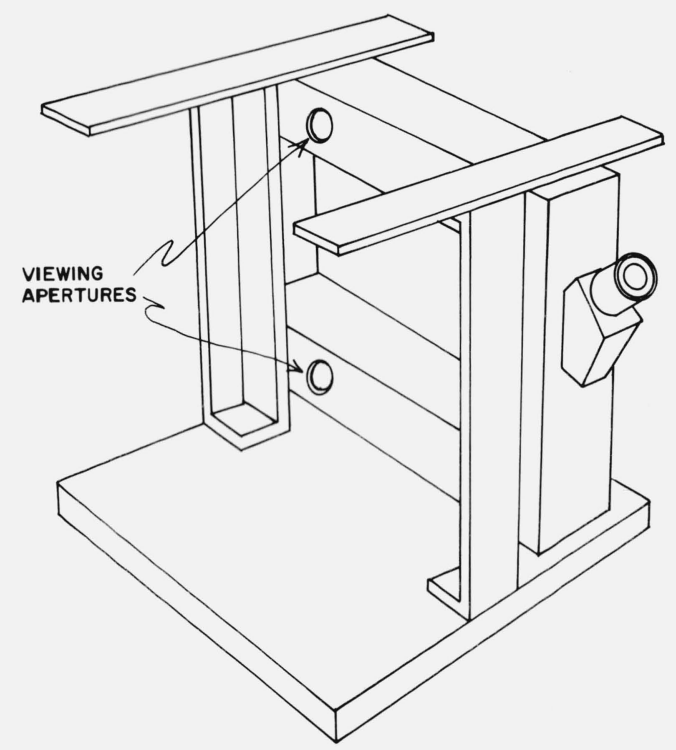

Figure 4. Dual microscope mounted in attenuator housing.

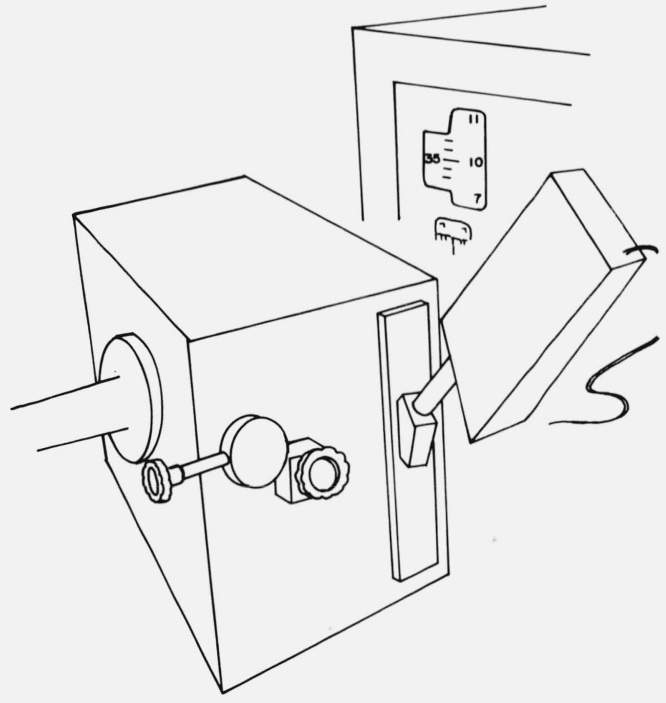

Figure 5. Modified attenuator housing.

to be the forces exerted on the rotating cylinder by the drive gear even though the finest quality triple A bearings had been used in the rotating joints. The problem was eliminated by driving the cylinder through a bellows as shown in figure 6 . This addition was not made to attenuators No. 2 and 3.

\subsection{External Leakage}

The effects of external leakage are quite subtle and in many cases are very difficult to identify. In the early design of the attenuators, this leakage caused nonrepeatability problems at the lower values of attenuation and instability at the higher values. The primary source of the leakage signal was determined to be the rotating joints.

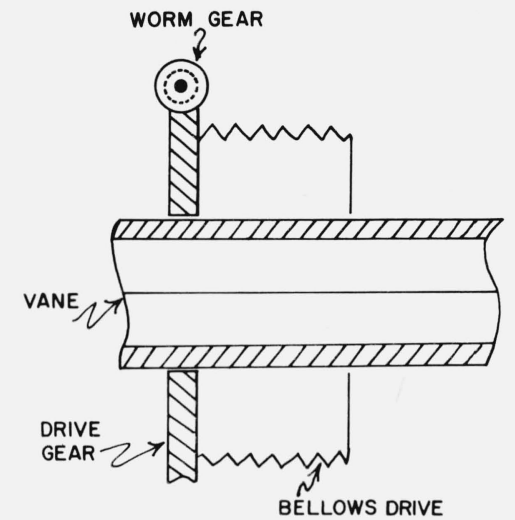

Figure 6. Bellows drive of attenuator No. 1 .

The addition of chokes alone did not provide sufficient attenuation to stop the leakage. In some cases, the leaked power is down only $40 \mathrm{~dB}$ from the incident power in the waveguide and it is rarely down more than $60 \mathrm{~dB}$. In the attenuators described here, the leakage was reduced to more than $120 \mathrm{~dB}$ below the incident power by liberal use of microwave-absorbing material in the design of the housing and rotating joints as shown in figure 7 .

\subsection{Internal Leakage}

Internal leakage is the result of insufficient attenuation of the parallel component of the wave (the component that is in the plane of the resistive card). The card absorption was checked by measuring the maximum attenuation that could be achieve with a particular card. For commercially available cards, this ranged from $110 \mathrm{~dB}$ to $135 \mathrm{~dB}$ at $9 \mathrm{GHz}$. The results of this leakage component is a deviation from the $\cos ^{2} \gamma$ law at the higher values of attenuation. Both Mariner [8] and James [9] analyzed

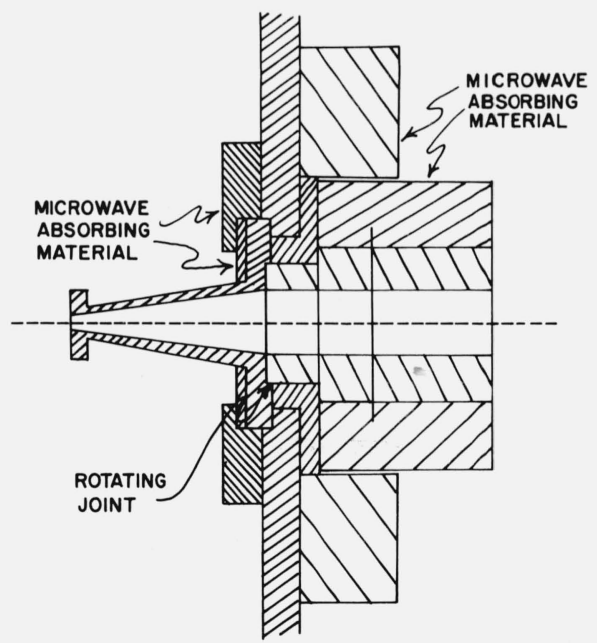

Figure 7. Addition of microwave absorbing material around rotating joints. 
this error. The actual effect of this leakage for the attenuators is shown in figures 8,9 , and 10 . Some work was done on the design of different types of cards but no improvement was achieved.

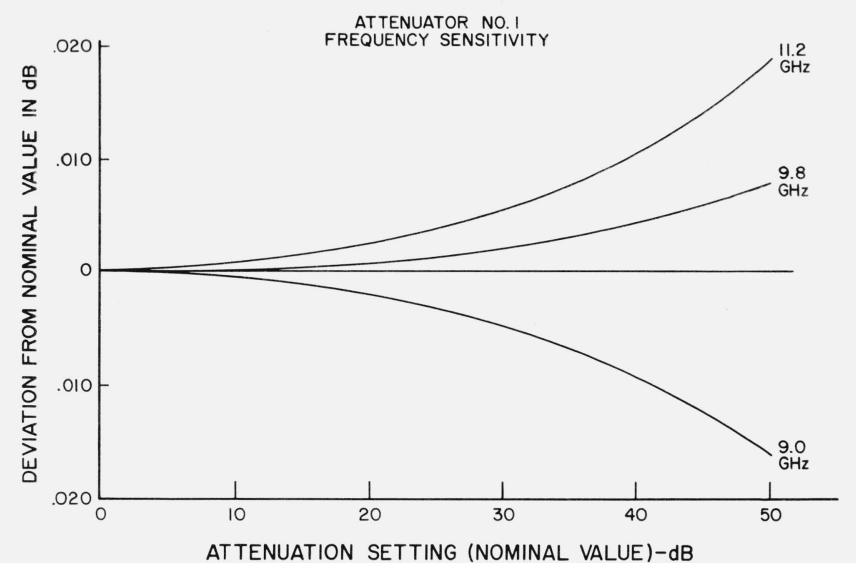

Figure 8. Frequency sensitivity of attenuator No. 1 .

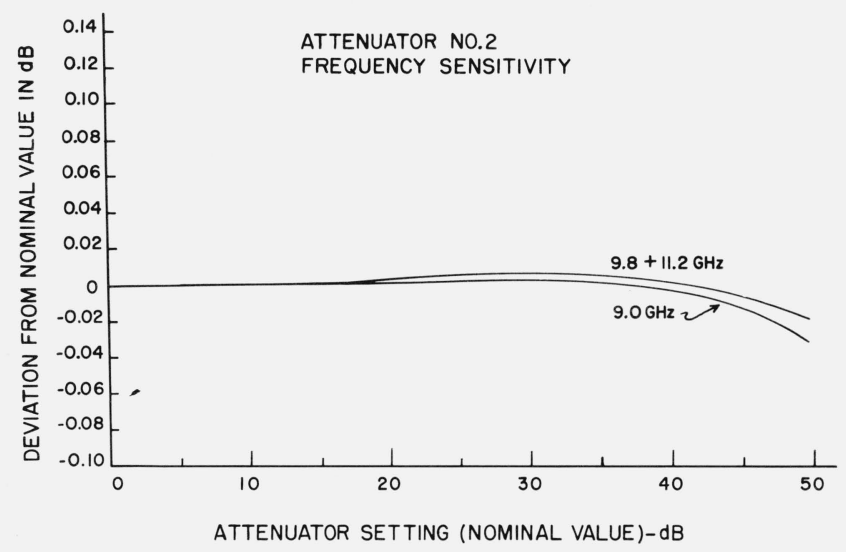

Figure 9. Frequency sensitivity of attenuator No. 2.

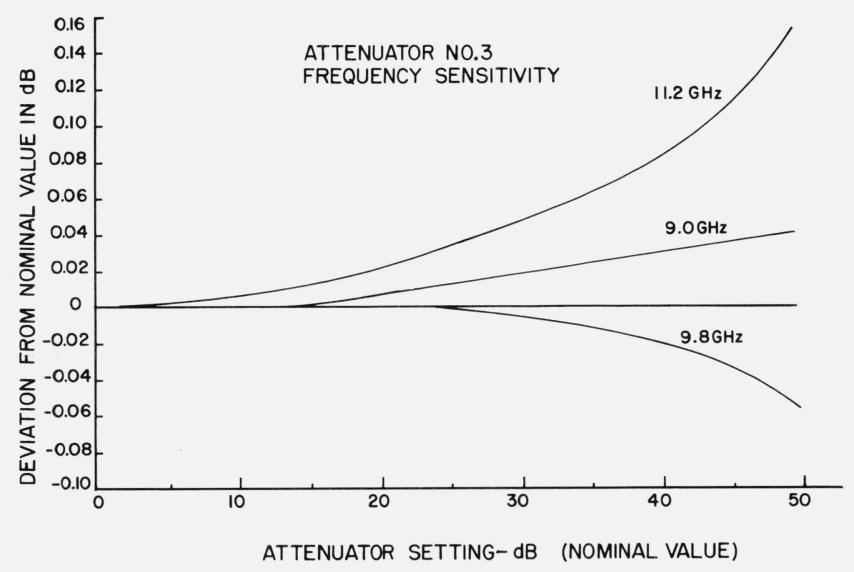

Figure 10. Frequency sensitivity of attenuator No. 3 .

\section{Results}

In order to test the attenuators over the desired $50 \mathrm{~dB}$ range, several techniques of attenuation measurement were used. The $d-c$ substitution [12] system is the most accurate technique of attenuation measurement available in the range of 0.01 to approximately $20 \mathrm{~dB}$. The modulated subcarrier $[13,14]$ technique is quite accurate in the range of 0.1 to $20 \mathrm{~dB}$ while the $\mathrm{i}-\mathrm{f}$ [15] substitution tech. nique is quite good in the range of 1 to $50 \mathrm{~dB}$. All the techniques are comparable over parts of the overlapping range up to $20 \mathrm{~dB}$. Above $20 \mathrm{~dB}$, the $\mathrm{d}-\mathrm{c}$ substitution technique loses resolution and the particular subcarrier system used for the measurements had not been carefully evaluated above $20 \mathrm{~dB}$ at the time of the measurements.

Attenuators No. 2 and No. 3 were calibrated by all three techniques of attenuation measurement at several values between 0.5 and $20 \mathrm{~dB}$ at $9 \mathrm{GHz}$ as shown in table 1. (Values above $20 \mathrm{~dB}$ were obtained by the $\mathrm{i}-\mathrm{f}$ tech-

TABle 1. Comparison of calibration data for the same attenuator by three different methods

\begin{tabular}{|c|c|c|c|c|}
\hline $\begin{array}{c}\text { Nominal } \\
\text { value, } \\
\text { dB }\end{array}$ & & $\begin{array}{c}\text { Average } \\
\text { measured } \\
\text { value, } \\
\text { dB }\end{array}$ & $\begin{array}{l}\text { Estimated } \\
\text { limits to } \\
\text { systematic } \\
\text { error, }\end{array}$ & $\begin{array}{c}\text { Standard } \\
\text { deviation, } \\
\mathrm{dB}\end{array}$ \\
\hline \multicolumn{5}{|c|}{ Attenuator No. 2.} \\
\hline 0.5000 & $\begin{array}{l}d-c \\
i-f \\
s c\end{array}$ & $\begin{array}{l}00.5006 \\
00.4990 \\
00.4996\end{array}$ & $\begin{array}{r}0.0006 \\
.0150 \\
.0050\end{array}$ & $\begin{array}{l}.0001 \\
.1000 \\
.0005\end{array}$ \\
\hline 1.0000 & $\begin{array}{l}d-c \\
i-f \\
s c\end{array}$ & $\begin{array}{l}01.0018 \\
01.0002 \\
00.9997\end{array}$ & $\begin{array}{l}.0013 \\
.0150 \\
.005\end{array}$ & $\begin{array}{l}.0006 \\
.0023 \\
.0016\end{array}$ \\
\hline 3.0000 & $\begin{array}{l}\mathrm{d}-\mathrm{c} \\
\mathrm{i}-\mathrm{f} \\
\mathrm{sc}\end{array}$ & $\begin{array}{l}03.0016 \\
03.0000 \\
02.9993\end{array}$ & $\begin{array}{l}.0047 \\
.0150 \\
.0050\end{array}$ & $\begin{array}{l}.0001 \\
.0023 \\
.0014\end{array}$ \\
\hline 6.0000 & $\begin{array}{l}d-c \\
i-f \\
s c\end{array}$ & $\begin{array}{l}06.0021 \\
05.9986 \\
05.9984\end{array}$ & $\begin{array}{l}.0049 \\
.0150 \\
.0050\end{array}$ & $\begin{array}{l}.0001 \\
.0028 \\
.0025\end{array}$ \\
\hline 10.0000 & $\begin{array}{l}d-c \\
i-f \\
s c\end{array}$ & $\begin{array}{l}10.0020 \\
09.9990 \\
09.9973\end{array}$ & $\begin{array}{l}.0053 \\
.0150 \\
.0050\end{array}$ & $\begin{array}{l}.0055 \\
.0013 \\
.0021\end{array}$ \\
\hline 20.0000 & $\begin{array}{l}d-c \\
i-f \\
s c\end{array}$ & $\begin{array}{l}20.0021 \\
19.9994 \\
19.9946\end{array}$ & $\begin{array}{l}.0100 \\
.0150 \\
.0100\end{array}$ & $\begin{array}{l}.0042 \\
.0013 \\
.0023\end{array}$ \\
\hline \multicolumn{5}{|c|}{ Attenuator No. 3.} \\
\hline 0.5000 & $\begin{array}{l}d-c \\
i-f \\
s c\end{array}$ & $\begin{array}{r}0.5002 \\
.4988 \\
.5007\end{array}$ & $\begin{array}{c}0.0006 \\
.0150 \\
.005\end{array}$ & $\begin{array}{r}0.0004 \\
.0010 \\
.0002\end{array}$ \\
\hline 1.0000 & $\begin{array}{l}d-c \\
i-f \\
s c\end{array}$ & $\begin{array}{l}1.0003 \\
0.9992 \\
1.0003\end{array}$ & $\begin{array}{l}.0013 \\
.0150 \\
.0050\end{array}$ & $\begin{array}{l}.0002 \\
.0010 \\
.0011\end{array}$ \\
\hline 3.0000 & $\begin{array}{l}d-c \\
i-f \\
s c\end{array}$ & $\begin{array}{l}3.0007 \\
3.0010 \\
3.0003\end{array}$ & $\begin{array}{l}.0047 \\
.0150 \\
.0050\end{array}$ & $\begin{array}{l}.0002 \\
.0010 \\
.0015\end{array}$ \\
\hline 6.0000 & $\begin{array}{l}d-c \\
i-f \\
s c\end{array}$ & $\begin{array}{l}6.0008 \\
6.0000 \\
6.0007\end{array}$ & $\begin{array}{l}.0049 \\
.0150 \\
.0050\end{array}$ & $\begin{array}{l}.0005 \\
.0023 \\
.0027\end{array}$ \\
\hline 10.000 & $\begin{array}{l}d-c \\
i-f \\
s c\end{array}$ & $\begin{array}{l}9.9996 \\
9.9992 \\
9.9994\end{array}$ & $\begin{array}{l}.0053 \\
.0150 \\
.0050\end{array}$ & $\begin{array}{l}.0016 \\
.0010 \\
.0025\end{array}$ \\
\hline 20.0000 & $\begin{array}{l}\mathrm{d}-\mathrm{c} \\
\mathrm{i}-\mathrm{f} \\
\mathrm{sc}\end{array}$ & $\begin{array}{l}20.0069 \\
19.9964 \\
20.0000\end{array}$ & $\begin{array}{l}.0100 \\
.0150 \\
.0100\end{array}$ & $\begin{array}{l}.0014 \\
.0013 \\
.0045\end{array}$ \\
\hline
\end{tabular}


nique only and are shown in table 3 ). The estimated systematic error for each system is the summation of the estimated limits to all of the known system errors (this gives the estimated maximum possible systematic error) and the standard deviation is determined from the measurement data.

The estimated true values for the attenuators given in table 2 are the average of the values obtained from the three different systems.

TABLE 2. Estimated true value for each nominal value determined from the average of the three different methods

\begin{tabular}{ccc}
\hline $\begin{array}{c}\text { Nominal } \\
\text { value, } \\
\mathrm{dB}\end{array}$ & $\begin{array}{c}\text { Estimated } \\
\text { true } \\
\text { value, } \\
\mathrm{dB}\end{array}$ \\
\hline \multicolumn{3}{c}{ Attenuator No. 2} \\
1.0000 & \\
3.0000 & 00.4997 \\
6.0000 & 01.0006 \\
10.0000 & & 03.0003 \\
20.0000 & 05.9997 \\
& Attenuator No. 3. & 09.9996 \\
0.5000 & 19.9987 \\
1.0000 & \\
3.0000 & 00.4999 \\
6.0000 & 00.9992 \\
10.0000 & 03.0005 \\
20.0000 & 06.0004 \\
& 10.0003 \\
& & 20.0018 \\
\hline
\end{tabular}

TABLE 3. Measured values-i-f substitution technique

\begin{tabular}{|c|c|c|c|}
\hline $\begin{array}{c}\text { Nominal } \\
\text { value, } \\
\text { dB }\end{array}$ & $\begin{array}{c}\text { Average } \\
\text { measured } \\
\text { value, } \\
\text { dB }\end{array}$ & $\begin{array}{l}\text { Estimated } \\
\text { limits to } \\
\text { systematic } \\
\text { error, } \\
\text { dB }\end{array}$ & $\begin{array}{c}\text { Standard } \\
\text { deviation, } \\
\text { dB }\end{array}$ \\
\hline \multicolumn{4}{|c|}{ Attenuator No. 2} \\
\hline 30.000 & 30.001 & \pm 0.018 & 0.001 \\
\hline 40.000 & 40.000 & \pm .028 & .003 \\
\hline 50.000 & 49.968 & \pm .085 & .004 \\
\hline \multicolumn{4}{|c|}{ Attenuator No. 3} \\
\hline 30.000 & 29.995 & \pm 0.018 & 0.003 \\
\hline 40.000 & 39.982 & \pm .028 & .003 \\
\hline 50.000 & 49.945 & \pm .085 & .003 \\
\hline
\end{tabular}

\section{Conclusion}

The development work outlined in this report confirms that over a limited range a precision-built, rotary-vane attenuator has excellent properties for a primary reference standard of attenuation difference. These properties are nearly ideal up to the attenuation value of $20 \mathrm{~dB}$. Above this value of attenuation the rotary-vane attenuator is an excellent working standard. (The attenuator needs calibrating because of the frequency-sensitivity problem.) Solution of the remaining two outstanding problems (frequency sensitivity and internal leakage) will estab- lish it as a primary reference standard over a much larger attenuation range.

The attenuator should find wide application for the evaluation of systems where it is not feasible to use section-by-section evaluation techniques. For example, in some of the dual channel i-f attenuation-measuring systems, the standard piston attenuator cannot be independently evaluated. In addition to being used in the straight rf substitution technique, this rotary-vane attenuator can be used in the same fashion that the $30 \mathrm{MHz}$ waveguidebelow-cutoff atenuator is presently used. For the higher frequencies (millimeter waves), a frequency down converter can be used to obtain the proper frequency and for the lower frequencies, an upconverter can be employed.

Another quite useful area for this rotary-vane attenuator is in the measurement of very small values of attenuation. To the authors' knowledge, there is no other way to achieve a change of attenuation of a few hundredths or tenths of the decibel to the accuracy and resolution that can be achieved with the ultra-precision rotary-vane attenuator.

\section{References}

[1] Southworth, G. C., (1959), Principles and Applications of Waveguide Transmissions, Ed., Princeton, J. J. (Von Nostrand, (1959) pp. 374-376.

[2] Hand, B. P., A precision waveguide attenuator which obeys a mathematical law, Hewlett-Packard J. 6, 1-2 (Jan. 1955).

[3] Larson, Wilbur, Analysis of rotation errors of a waveguide rotary-vane attenuator, IEEE Trans. Instr. Meas. IM-12, No. 2, 50-55 (Sept. 1963).

[4] Larson, Wilbur, Table of attenuation error as a function of vane-angle error for rotary-vane attenuators, Nat. Bur. Stand. (U.S.), Tech. Note 177, 156 pages (May 1963).

[5] Larson, Wilbur, Table of attenuation as a function of vane angle for rotary-vane attenuators $\left(A=-40 \log _{10} \cos \theta\right)$, Nat. Bur. Stand. (U.S.), Tech. Note 229, 188 pages (Jan. 1965)

[6] Larson, Wilbur, Gearing errors as related to alignment techniques of the rotary-vane attenuator, IEEE Trans. Instr. Meas. IM-14, 117-123 (Sept. 1965).

[7] Larson, Wilbur, Analysis of Rotationally Misaligned Stators in the Rotary-Vane Attenuator, IEEE Trans. Instr. Meas. IM-16, No. 3 (Sept. 1962).

[8] Mariner, P. F., An absolute microwave attenuator, Proc. IEE, pp. 415-419 (Sept. 1962).

[9] James, Allan V., A high-accuracy microwave attenuation standard for use in primary calibration Laboratories, IRE Trans. Instr. I-11, 285-290 (Dec. 1962).

[10] Gainsborough, G. F., A method of calibrating standard-signal generators and radio-frequency attenuators, J. IEE (London) 94, Part III, 203-210 (May 1947).

[11] Grantham, R. E., and Freeman, J. J., (June 1968), A standard of Attenuation for Microwave Measurements, Trans. AIEE 67, 329-335 (June 1968).

[12] Engen, G. F., and Beatty, R. W., Microwave attenuation measurements with accuracies from 0.0001 to 0.06 decibel over a range of 0.01 to 50 decibels, J. Res. Nat. Bur. Stand. (U.S.), 64C (Eng. \& Instr.), No. 2, 139-145 (Apr.-June 1960).

[13] Schafer, G. E., and Bowman, R. R., A modulated sub-carrier technique of measuring microwave attenuation, Proc. IEE (London) 109, Part B. Suppl. No. 23, 783-786 (May 1962).

[14] Little, William E., Further analysis of the modulated subcarrier technique of attenuation measurement, IEEE Trans. Instr. Meas. 13, 71-76 (June-Sept. 1964).

[15] Weinschel, B. O., and Sorger, G. U., Waveguide below cutoff attenuation standard, Acta IMEKO III, 407-424 (1964).

(Paper 75Cl-307) 